\title{
Formation of Healthy Lifestyle in Students' Training in System of Continual Linguistic Education
}

\author{
Natalia Torunova ${ }^{1}$, Margarita Pogodaeva ${ }^{2}$, and Tatiana Davydova ${ }^{3}$ \\ ${ }^{1}$ Irkutsk State University, Pedagogical Institute, Foreign Languages and Linguodidactics Department, 664025 Irkutsk, Russia \\ 2 Irkutsk State University, Pedagogical Institute, Geography, Life Safety and Methods of Teaching Department, 664025 \\ Irkutsk, Russia \\ ${ }^{3}$ Baikal State Universities, Foreign Languages Department, 664025 Irkutsk, Russia
}

\begin{abstract}
The analysis of the health index dynamics of children, teenagers and young people of Russia during the last two decades testifies that there is a lasting tendency of decline of physical, mental and moral health of those under teaching. The social negative phenomena like tobaccosmoking, beer drinking and risky sexual behavior have become widely spread. The absence of a continual system of pedagogical education focused on health value and healthy lifestyle is one of the major reasons of low efficiency of the work carried out by educational institutions. The article substantiates the potential possibilities of a foreign language as an aspect to provide those trained with continual formation of a healthy lifestyle and examines the work done within the frame of curriculum and extra-curriculum activities united by one topic.
\end{abstract}

\section{Introduction}

The reform of education which is taking place nowadays in Russia from the pre-school level up to the post-graduate level can provide the favorable conditions for the improvement of children's health, taking into account risk factors for their health and development, which appear during study and improvements in teaching and educational work for the formation of health culture. Under "health culture", we understand social-psychological individual activity aimed at promoting, reserving and mastering rules, principles and traditions of healthy lifestyle, turning it into internal needs. However, understanding this cultural phenomenon is dubious and it has different interpretational meanings in different social and professional backgrounds $[1,2]$. Neil Maycroft states that healthy lifestyle allows one to bridge social, gender and ethnic diversities [2]. To be healthy nowadays becomes modern and prestigious.

Healthy lifestyle is, first of all, cultural lifestyle. The basic idea of this phenomenon is a person's care about physical, psychic health and moral health as the highest value. Healthy lifestyle is a means of lifesustaining activity aimed at preserving and improving of health as conditions and pre-requirement of individual being and one's development.

Nowadays the great experimental and clinical experience is accumulated and it demonstrates negative impact of bad habits (alcohol abuse, smoking, hypodynamia, junk food) into person's cardiovascular sys- tem, breathing and nervous systems, metabolism, psychic state $[3,4,5,6,7,8]$. At the same time, the formation of healthy lifestyle habits still remains a burning problem.

The cultivation of healthy lifestyle has to be implemented at the pre-school level and junior level when the vital life attitude and the basis for the biological and sociological health component are being formed. The formation of the principles of healthy attitude to oneself in early childhood must follow up a person all his life. In such context, we shall discuss the system of continual health protection education in general and cultivation of healthy lifestyle culture in the process of foreign language communication in particular.

It is principally important that the formation of student's healthy lifestyle takes place within the understanding of life priorities, and particularly, of health value, cultivation of communicative culture, ethic and regional traditions etc. In cultivation of healthy lifestyle culture, it is important for educators (carers, teachers, instructors) to focus their attention on the formation of student's motivation for health and learning the basics of healthy lifestyle.

Today a lot of work is being carried out for the study of health condition of the younger generation and educational factors (hypodynamia, psychic tense, chronic stress etc.) which influence its formation. The experience of cooperation between Health Department and Department of Education in carrying mutual work is accumulated and it is resulted in design and 
implementation of modern health protection and pedagogical technologies.

Different forms of psychic-pedagogical following up of pre-school children, schoolchildren, students, disabled persons and those who need special conditions for education are being improved now. Different events are carried out to form healthy lifestyle, to prevent deviant behavior and abuse of psychoactive substances, suicides $[9,10]$.

In the documents of the $16^{\text {th }}$ congress of European Union of school and university medicine and health, the attention was drawn to the necessity of the formation of healthy lifestyle in the system of continual education:

- to pay prior attention to the health promotion at every child care centers, all schools and universities;

- to implement on the regular basis medicalpedagogical monitoring of child's health and his development;

- to motivate teachers, doctors and parents to share the knowledge about health development methods of teaching;

- to study and advertise the experience of European health school system;

- to change the aims and tasks of professional teacher's training for them to realize physical, psychic, moral and intellectual health of children and their own;

- to establish public associations of parents which can provide democratic and state-social control of education management, help to unite the efforts of a family, school and society for harmonious development of younger generation;

- to establish health care centers to coordinate the efforts of educators, doctors aimed at preservation and health promotion of children and students;

- to initiate additional measures of financial and moral support for the educational institutions, in which the educators implement health promotion technologies in education and have stable positive practical results.

The dynamic analysis of children's health indices of children's, teenagers' and the youngsters' health in Russia for the last two decades indicates the lasting tendency of decay of physical, psychic and moral health. Among the new-born children are healthy only about $30 \%$ and to the moment of enrolling to school only $15 \%$ of them are healthy, and only about $5 \%$ are healthy among the school-leavers. From the primary school up to leaving the secondary school, the number of children with neuro-psychic disorders increases from $6 \%$ up to $12 \%$, with the shortsightedness - from $4 \%$ up to $12 \%$; with postural disorders - from $2 \%$ up to $16 \%$. The major part of them are schoolchildren with aggravated chronic diseases [12].

\section{Results and Discussion}

The low level of student's health is one of the important factors, which harms greatly the health of schoolchildren and students. The low level is confirmed by the written questionnaires, which are held annually for the first-year students in Irkutsk State University. According to the results (2016-2017), the respondents who go in for sports regularly, are only $10 \%$ or $12 \%$; those who do not keep to daily regimen and study at nights are about $28 \%$ up to $40 \%$. Among the first-year students smoking, beer-drinking (mainly) are widely spread. When asked how they care about their health, only $60 \%$ of the students answered that it is not sufficient and might be better. Among the reasons preventing them from caring about their health are: objective-the lack of time, the need for some additional material expenses; almost every second students mentioned the subjective reasons: the lack of will, more important tasks and laziness. The answers show the unformed understanding of the importance of health as a value and the absence of the motivation for healthy lifestyle. In modern conditions the increase of health culture by means of education might be provided by implementation of special subjects as well as by including the questions about healthy lifestyle into the content of other academic courses e.g. through the contextual teaching.

New concept of health protection of educational activity of children's, teenagers and the young is worked out and it is based on the idea that health protection system is the system in the framework of which all levels of human formation are provided with the realization of basic motives (needs and meanings). Therefore, in such case, the conditions for complete development of human's abilities are created and it allows him to realize his personal uniqueness, his correct self-identity in life and spontaneous (in the process of self-actualization) formation of basic health components.

The top-priority in the concept is placed for upbringing as the process of forming such hierarchy of needs and meanings, which are favorable for a person self-realization in all variety of his potential abilities and cultivate his healthy life activities. In more general sense, this concept can be formulated as follows: from valeologically grounded self-development and spontaneous acquirement of basic skills of educational activity (pre-school, primary school education), through self-understanding and self-meaning (5-9 forms), and to self-improvement, self-identity and healthy lifestyle (9-11forms and the following levels of education)

Within the framework of health protection and health formation concept of education, the task for the necessity of cultivation healthy life for children is set and there is formation of their science-based understanding of the idea of healthy lifestyle and formulation of individual valeologically grounded lifestyle. Educational environment must provide the possibilities for personal development not only of a child but also of teachers and other participants of the educational process. The system of values, which focuses on humanistic secured child's development, is supposed to create social-pedagogic adaptive-enriching environment $[9,10]$ 
Taking into account the life style components, the following concept of healthy lifestyle is suggested: from moral, physical and gender upbringing, formation of individual way of psychic self-regulation and food behavior, hygienic, physiological, ecological and medical knowledge to healthy lifestyle and somatic health.

In the secondary school (5-9 forms), the main pedagogical task in health formative education is in the formation of individual way of health promotion, psychic self-adjustment and sex behavior by the way of creating such reflective environment in which it becomes possible for self-identity (one's personal psychological and physiological features, specific personal pubertas) the ability to set challenging tasks, which concern the understanding of the nature of healthy lifestyle, analysis and correction of one's personal lifestyle.

In a secondary school, the main pedagogical task in the area of health formative education is set in working out personal healthy lifestyle, acquirement of knowledge and skills for illness prevention, readiness for a family life and children's upbringing. The solution of the task is provided by creation of the conditions for analysis and self-analysis, individual selection of the ways of studying learning materials and for self-education.

The formation of the health of pre-school child takes place in the process of active integration of healthy life technologies in educational environment. It is thought that the formation of healthy lifestyle is realized throughout of all educational areas. According to the tasks and content of psychologicalpedagogical work in pre-school educational institutions, such integration is possible to other areas: social-communicative development, cognitive development, speech development; artistic-aesthetic development; physical development.

The content of educational area "Health" is aimed at achieving the goals in child health protection and the formation of health culture by means of the following tasks' solution:

- protection and strengthening of physical and psychic health of a child;

- cultivation of cultural-hygienic skills;

- formation of primary insights into healthy lifestyle.

The methodology of healthy formative education in kindergarten and in primary school is in free game playing and creative work mainly by means of imitation, practical tasks, insight experience and other forms of productive behavior, it helps the formation of motivational basis for hygienic behavior, secured life, moral-psychological component healthy lifestyle and sex education.

Intercultural education plays today a very important part in a complete educational system related to the person's formation aimed at health culture. A foreign language as a means of communication and a secondary way of reality cognition at the same time carries out cultural function. Language does not only reflect the reality but it interprets it. Any language, as well as a foreign one, creates particular reality in which a person lives. The principle of co-learning of language and culture provides precondition of realization of strategic goals of teaching foreign language formation of communicative competence. A foreign word provides resulting impact on feelings, emotions, mind and, finally, on students' behavior which motivate them to acquire health culture. The authors gained the long-term experience of health culture formation and healthy lifestyle of students and preschool children by means of a foreign language who studied in different educational institutions.

Let us consider the possibilities of educational integration on the examples of teaching healthy lifestyle and secured behavior in the process of teaching preschool senior children. By using cognitive activity in the area of secured life with the aims of learning foreign language allows solving the following tasks:

1) to intensify motivation of studying a foreign language by means of enriching the lexis with the information which is interesting for children and involving pre-school children into the activity providing personal safety with the use of a foreign language;

2) to make use of the words and phrases practically aimed at providing personal safety;

3) to provide stability of memorizing the words and phrases by including foreign lexis in roleplaying games on the topic "health";

4) to enrich the vocabulary of everyday use for preschool children with the words on the topics "Health", "I am in the city", “ My family";

$5)$ to teach pre-school children to use word and phrases from a foreign language on the topics "Safety", "Health" in everyday communication; to give information about oneself, to express request, to think over the dangerous situations and to use it for the other practices in the areas of personal safety [11]

Teaching a foreign language is a way of formation of the second personality through understanding the culture of the language under study, one's own culture among other things, and health culture as its systemic part. So, one learns to follow healthy lifestyle consciously and subconsciously by means of a foreign language and with the language of knowledge, skills and habits.

Accumulated by the students' knowledge about health culture of their own country allows them to compare it with the information about health of the peers living in foreign countries and begin a dialogue of cultures using foreign languages. Such sub-subject oriented communication provides successful exchange and, therefore, mutual understanding of the partners in intercultural communication.

The success of such intercultural communication may be achieved under certain conditions. First of all, it is a competent approach in a language teacher training. It, in its turn, presupposes the adequate level of communicative, psychological-pedagogical and methodological competencies in a future linguist- 
teacher training. First of all, it is any foreign language teacher, as well as, a teacher of other subjects who should realize that his own health is of the highest value. It is supposed that the teacher of a foreign language as a bearer of health culture by means of foreign communication, by means of the process of intercultural communication, the system of curriculum and extra-curriculum activities on cross-cutting topics and adequate forms of extra-curriculum activities, as well as, a teacher as personality promotes the cultivation of student's cultural behavior. It is necessary for the teacher to have a certain number of integrated knowledge, skills and habits.

The authors of the article are the implementators of the integrated, prolonged project "Health throughout of education: cultivation of health culture and prophylactics of negative social acts of young learners by means of a foreign language communication".

The project was and is still being carried out and put into practice in some stages. The first stage was devoted to the outreach, awareness-raising and analytical work. The issues of prophylactics of addictions were included into the lectures on medical and hygienic training. During the extra-curriculum activities, different forms and methods of personal, social and health education influence were used: lectures, discussions, exhibition of special literature in the library, visual aid room and design of special display stands and corners, etc.

During the second stage, different active forms and methods of psychological and pedagogical effects were used: instructional playing design, playing mode trainings, discussions, brain-storming, role-play, media-forums. During this stage, the work of risk estimation for health was carried out by using the tests and questionnaires for defining constituent components of healthy lifestyle. Individual health programs aimed at overriding and correction identified risk factors were worked out.

The third stage was devoted to the analysis of the results of foreign language communication influence on the formation of health culture on the basis of the textbook. "Health culture training for students and pupils of senior grades in the process of intercultural communication study"

The particular feature of the project carried out by the authors in the East-Siberian region is an innovative integrated approach to the content and teaching of a foreign language by the use of its possibilities of influence of health culture on the students and, at large, on the personal development.

The aim of the project is to form the student's needs and motivation health and primary prophylactics of negative social acts as a global phenomenon of cultural competence. The effectiveness of using potential possibilities of the intercultural communication in cultivating health culture is convincingly proved by the theoretical ground and empirical implementation of the project in different educational institutions of East-Siberian region, Primorsky and Khabarovsky krai.
Continual foreign language education from preschool age up to the post-graduate level becomes a very important condition for effective cultivation of health culture in the process of intercultural communication.

Inclusion of health culture formation into the content of all kinds of activities (projecting, organizational, communicative-teaching, monitoring, gnostic, researching) of a foreign language teacher is considered as one of the important conditions in the progress of cultivating healthy lifestyle.

The novelty of the idea is in the fact that in scientific-theoretical and practical aspects there are few researches and publications reflecting the possibilities of the influence of a foreign language communication on the development of health culture. We have to state that teachers/ instructors of a foreign language still underestimate the possibilities and specificity of the subject for cultivating health culture through the process of the formation of speech and sociocultural competences. At the same time, the teachers who realize the necessity of a foreign language influence on the cultivation of health culture suffers from the lack of authentic texts of valeological nature and the lack of the guidance methods to work with them. Some of the topics are of penetrating nature and may be used on the different levels of a foreign-language teaching.

The integrated textbook designed by the authors "Health culture training for students and pupils of senior grades in the process of intercultural communication study" to a certain extent bridges the gap [12].

The uniqueness of the book is in the use of great reserved possibilities of continual education by means of a foreign language for cultivating health culture of the students.

The textbook consists of: content and design of the universal integrated prolonged elective course (1-3 years), which can be used in different types and forms of educational institutions, among other non-linguistic institutions;

texts collection of valeological nature, which contains the authentic texts on four languages (English, French, German, Russian) supplemented by instructional guidelines;

- questionnaires; identification; tests for health and working capacity risk (IHP);

The formation of healthcare competencies for linguist-teachers is carried out in the system of curriculum and extra-curriculum activities in the framework of such subjects: language practical course, practical course of cultural communication, health care education, methods of a foreign language teaching.

When drafting the individual health program, the authors used the innovative psychological approach for increasing student's motivation to healthcare behavior. The strategic line of the approach is in conducting by each student self-esteem and self-analysis of the indices of health reserve and behavioral risks of 
its decline. For the realization of this strategic line, the tests and questionnaires on the important structural components of healthy lifestyle were elaborated. On the basis of the analysis of the personal behavioral risks for health, a motivation basis is formed to elaborate a valid individual health program with account of personal needs.

According to the results of the students' written anonymous questioning in Irkutsk State University after undergoing the course and putting IHP into practice (2006-2016), the following inferences were made. From $60 \%$ up to $80 \%$ of the students changed their behavior focusing their attention on health and healthy lifestyle. They increase their physical activity, regulate their daily routine, optimize nutrition; some of the students (mainly girls) gave up smoking or cut its intensity.

\section{Conclusion}

The process of health culture and healthy lifestyle formation as its important component must be provided on all levels of school education (from primary to post-graduate) and cross all the educational areas/ subjects/courses in the system of curriculum and extra-curriculum classes: clubs, societies, sport sections. Modern Federal state educational standards direct the activity of all educational institutions of all levels at realization of health pedagogy in the educational process. For continual support of health protection in educational process the integration of pre-school, secondary, professional and supplementary education is necessary. Continual education is considered now as the leading concept for future reforms and novelties in economic and social spheres.
1. J. Coreil, J. S. Levin, International Quarterly of Community Health Education 5, 2: pp. 103114., (1984)

2. N. Maycroft, Capital \& Class 28, 3: pp. 61-75 (2004)

3. J.A. Staessen, R. Fagard, A. Amery, Am J Hypertens 7, 685 (1994)

4. J. A Staessen, L. Bieniaszewski, K. Pardaens, V. Petrov, L. Thijs, R. Fagard, J.Royal Soc. Med. 89, 9, 484 (1996)

5. R. Philipp, A. Hughes, F. Mackley, G. Fletcher, Health Educ. J. 47, 1: pp. 26-28 (1988)

6. E. Abildsnes, E.Meland, G. B. Samdal, T. H. Stea, T. Mildestvedt, Scand J Public Health 44, 7 (2016)

7. K. R Hebert, Br. J. Occup. Ther. 81, 3, 162 (2017)

8. Chiung-Yu Huang, Hui-Ling Lai, Yung-Chuan Lu, Wen-Kuei Chen, Shu-Ching Chi, Chu-Yun Lu, Chun-I Chen, Biol. Res.Nurs. 18, 1, $82(2015)$

9. N.P. Abaskalova, A.Yu. Zverkova, Siberian Pedagogical Journal. 5, 182 (2013)

10. A.Yu. Zverkova, N. P. Abaskalova, E. M. Kazin, Valeologiya 2,.34 (2015)

11. M.V. Pogodayeva, T.I. Nikulina, Doshkol'noye vospitaniye 7, 10 (2015)

12. V. A. Sherstenikina, N.I. Torunova, E. A. Zhitnitskaya Health culture training for students and pupils of senior grades in the process of intercultural communication study (it was approved by the Federal Agency of Education of Russian Federation and recommended as a textbook for the University students) (2005)

\section{References}

